\title{
Insight into inflammatory cell and cytokine profiles in adult IgA vasculitis
}

\author{
T. Kuret ${ }^{1}$ (1) $\cdot$ K. Lakota $^{1,2} \cdot$ P. Žigon ${ }^{1} \cdot$ M. Ogrič ${ }^{1} \cdot$ Snezna Sodin-Šemrl ${ }^{1,2} \cdot$ S. Čučnik ${ }^{1,3} \cdot$ M. Tomšič ${ }^{1,4} \cdot$ A. Hočevar ${ }^{1}$
}

Received: 17 May 2018 / Accepted: 23 July 2018 / Published online: 2 August 2018

(C) The Author(s) 2018

\begin{abstract}
Immunoglobulin A vasculitis (IgAV) is an immune complex, small vessel vasculitis with dominant IgA deposits in vessel walls, predominantly affecting the pediatric population. However, adults frequently have more severe gastrointestinal tract (GIT) and renal involvements as compared to children. Our aim was to study serological and cellular biomarkers to support clinicians in their diagnosis and the course of IgAV in adult patients. This cross-sectional study included 62 adult IgAV patients and 53 healthy blood donors (HBDs). Demographic and clinical data, as well as routine laboratory tests, were meticulously analyzed. Serum levels of IL-1 $\beta$, IL-2, IL-6, IL-8, IL-9, IL-10, IL-17A, IL-23, TNF- $\alpha$ and serum amyloid A (SAA) were measured. Percentages of neutrophils, lymphocytes, and monocytes with neutrophil expression of L-selectin and integrin $\alpha \mathrm{M}$ were determined by flow cytometry. SAA (12-fold), IL-6 (3-fold), IL-8 (2-fold), and TNF- $\alpha$ (2-fold) were significantly elevated in sera of adult IgAV patients compared to HBDs. There was a $16 \%$ elevation in neutrophils in IgAV patients, with IgAV neutrophils showing significantly higher CD62L surface expression. IgAV patients with GIT involvement exhibited elevated numbers of leukocytes, neutrophils, and neutrophil/lymphocyte (NLR), but lower neutrophil CD11b expression, as compared to IgAV patients without GIT. IgAV patients exhibit a low-medium grade inflammatory, neutrophil-driven response. Patients with GIT can be distinguished by their elevated NLR.
\end{abstract}

Keywords Cytokines $\cdot$ IgA vasculitis $\cdot$ Immunophenotyping $\cdot$ Inflammation $\cdot$ Neutrophil granulocytes

Rheumatology in Slovenia: Clinical practice and translational research

Electronic supplementary material The online version of this article (https://doi.org/10.1007/s10067-018-4234-8) contains supplementary material, which is available to authorized users.

\author{
Snezna Sodin-Šemrl \\ ssodin1@yahoo.com \\ T. Kuret \\ tadejakuret@gmail.com \\ K. Lakota \\ katja.lakota@guest.arnes.si \\ P. Žigon \\ polona.zigon@guest.arnes.si \\ M. Ogrič \\ manca.ogric@gmail.com \\ S. Čučnik \\ sasa.cucnik@kclj.si
}

M. Tomšič
matija.tomsic@guest.arnes.si

A. Hočevar

alojzija.hocevar@gmail.com

1 Department of Rheumatology, University Medical Centre Ljubljana, Vodnikova cesta 62, SI-1000 Ljubljana, Slovenia

2 Faculty of Mathematics, Natural Science and Information Technologies, University of Primorska, Glagoljaška ulica 8, SI-6000 Koper, Slovenia

3 Faculty of Pharmacy, University of Ljubljana, Aškerčeva cesta 7, SI-1000 Ljubljana, Slovenia

4 Faculty of Medicine, University of Ljubljana, Korytkova ulica 2, SI-1000 Ljubljana, Slovenia 


\section{Introduction}

Immunoglobulin A vasculitis (IgAV) is a small-vessel, immune complex leukocytoclastic vasculitis, characterized by dominant IgA deposits in vascular walls [1]. It represents the most common primary vasculitis in the pediatric population $[2,3]$; however, it is also frequent in adults, as recently shown [4].

Clinical signs and symptoms of the disease include cutaneous purpura, joint, gastrointestinal tract (GIT), and renal involvement; however, they differ greatly depending on the age of the patients $[5,6]$. Adults develop systemic involvement more frequently compared to children, with greater risk of severe bowel ischemia and chronic renal failure [7-11].

There are currently no diagnostic criteria for IgAV. The updated classification criteria for pediatric IgAV (EULAR/ PRINTO/PRES classification criteria) [12], performed well also in adult IgAV [13]. Yet, the final diagnosis leans on histological characterization of IgAV $[1,14]$. However, not all the expected significant changes are present in biopsy tissue, neither is IgA deposition pathognomonic for IgAV [14]. In approximately $10-20 \%$ of patients, GIT or joint symptoms may occur before the onset of skin purpura and setting an appropriate diagnosis of IgAV is difficult, when there is an atypical presentation $[14,15]$.

It would be advantageous to find a serological biomarker or group of analytes, which could support clinicians in their diagnosis in such cases. Moreover, there is a need of prognostic markers that would predict patients who are at risk of developing severe GIT and renal involvement, as well as complications during disease progression in order to facilitate appropriate therapeutic management of these patients [14].

The aims of this study were to evaluate serum levels of cytokines and acute phase proteins as well as determine the distribution of neutrophils, lymphocytes, and monocytes, together with neutrophil surface expression of L-selectin (CD62L) and integrin $\alpha \mathrm{M}(\mathrm{CD} 11 \mathrm{~b})$, among adult IgAV patients.

\section{Materials and methods}

\section{Human subjects}

We included 62 adult, treatment-naïve IgAV patients, with histologically proven disease $[12,13]$. For comparison, sera samples of 53 and peripheral blood of 15 healthy blood donors (HBDs) were obtained. All samples were fully anonymized, before we assessed them, and all subjects signed informed consent. The study was approved by the Slovene National Medical Ethics Committee (\#99/04/15 and \#65/01/17).

\section{Data collection}

The medical records from IgAV patients were analyzed and the following was recorded: age, gender, body mass index, smoking status, duration of clinical symptoms, and signs before sampling, concurrent infections, past malignancy, clinical signs and symptoms, Birmingham vasculitis activity score (BVAS), and results of routine laboratory testing.

\section{Laboratory parameters}

Erythrocyte sedimentation rate and concentration of Creactive protein, complete blood count with differential, basic biochemistry panels including electrolytes, creatinine, urea, serum protein electrophoresis, serum immunoglobulin (Ig) A, M, G levels, and urine analysis were determined.

\section{Cytokine and serum amyloid $A$ measurement}

Concentrations of IL-1 $\beta$, IL-2, IL-8, IL-9, IL-10, IL-17A, IL23 , and TNF- $\alpha$ were measured in sera of IgAV patients and HBDs by AtheNa Multi-Lyte (Luminex xMAP Technology) using human pre-mixed multi-analyte kits (R\&D Systems). IL-6 sera proteins levels were measured by ELISA (Invitrogen). The concentrations of serum amyloid A (SAA) were determined using immunonephelometry (BN Prospec System, Siemens). All sera samples were collected following blood clotting and centrifugation at $3000 \times \mathrm{g}$ for $5 \mathrm{~min}$, aliquoted, and stored at $-20^{\circ} \mathrm{C}$ until ready for further analysis.

\section{Flow cytometry}

Venous blood was drawn from IgAV patients and HBDs and collected into heparin-containing tubes. Whole blood immunophenotyping was performed using 7-Color Immunphenotyping kit (Miltenyi Biotec). Briefly, $100 \mu \mathrm{l}$ of whole blood was incubated with $10 \mu \mathrm{l}$ immunophenotyping reagent for $10 \mathrm{~min}$ in the dark, at $4{ }^{\circ} \mathrm{C}$. After incubation, erythrocytes were lysed using Red Blood Lysing Solution (Miltenyi Biotec). Neutrophil phenotyping was performed in $50 \mu \mathrm{l}$ of whole blood, incubated for $30 \mathrm{~min}$ at $4{ }^{\circ} \mathrm{C}$ in the dark with mouse anti-human antibodies to $\mathrm{CD} 16$ (conjugated to $\mathrm{PE}$, clone eBioCB16, eBioscience), CD62L (conjugated to PE-Cyanine 5, clone DREG56, eBioscience), and CD11b (conjugated to APC, clone ICRF44, eBioscience). After incubation, samples were lysed, using Whole Blood Lysing Reagent Kit (Beckman Coulter). All samples were analyzed using flow cytometer MACSQuant Analyzer 10 (Miltenyi Biotec). Analysis of flow cytometry data was performed using MACSQquantify (Analysis Software version 2.8) and FlowLogic (Flow Cytometry Analysis Package, version 700.0a). 


\section{Statistical analysis}

The normality of distribution was determined by ShapiroWilk test. Due to non-normal distribution of the data, summary statistics were expressed as medians and $25-75$ th percentiles $\left(\mathrm{Q}_{25}-\mathrm{Q}_{75}\right)$, and nonparametric tests were performed. Mann-Whitney U test was used to compare continuous variables between IgAV patients and HBDs, or between IgAV patients with/without different clinical symptoms and signs. Spearman's rank correlation was calculated to measure the correlation between parameters. All statistical analysis was

Table 1 Demographics, clinical, and laboratory data of IgAV patients

\begin{tabular}{|c|c|}
\hline \multicolumn{2}{|l|}{ Demographic data } \\
\hline Number of patients & 62 \\
\hline Median age in years $\left(\mathrm{Q}_{25}-\mathrm{Q}_{75}\right)$ & $56.0(38.9-74.8)$ \\
\hline Number of men $(\%)$ & $32(52)$ \\
\hline Median duration of symptoms (days) $\left(\mathrm{Q}_{25}-\mathrm{Q}_{75}\right)$ & $10(5-19)$ \\
\hline Median body mass index $\left(\mathrm{kg} / \mathrm{m}^{2}\right)\left(\mathrm{Q}_{25}-\mathrm{Q}_{75}\right)$ & $26.3(22.7-30.3)$ \\
\hline Number of current and formal smokers (\%) & $33(53)$ \\
\hline \multicolumn{2}{|l|}{ Symptoms and signs $\mathrm{n}(\%)$} \\
\hline General symptoms & $13(21)$ \\
\hline Fever & $7(11)$ \\
\hline Loss of weight & $7(11)$ \\
\hline Skin purpura & $62(100)$ \\
\hline Generalized skin purpura & $35(56)$ \\
\hline Skin necrosis & $28(45)$ \\
\hline Joint involvement & $25(40)$ \\
\hline Arthralgia & $25(40)$ \\
\hline Arthritis & $9(15)$ \\
\hline GIT involvement & $24(39)$ \\
\hline Renal involvement & $22(35)$ \\
\hline GIT and renal involvement & $11(18)$ \\
\hline Median BVAS $\left(\mathrm{Q}_{25}-\mathrm{Q}_{75}\right)$ & $6(2-12)$ \\
\hline Concurrent infection & $6(10)$ \\
\hline Past malignancy & $6(10)$ \\
\hline \multicolumn{2}{|l|}{ Median laboratory values $\left(\mathrm{Q}_{25}-\mathrm{Q}_{75}\right)$} \\
\hline $\operatorname{ESR}(\mathrm{mm} / \mathrm{h})$ & $32.4(14.0-53.3)$ \\
\hline $\mathrm{CRP}(\mathrm{g} / \mathrm{l})$ & $23.0(5.0-62.3)$ \\
\hline Number of leukocytes $\left(10^{9} / 1\right)$ & $7.8(6.5-10.1)$ \\
\hline Number of lymphocytes $\left(10^{9} / 1\right)$ & $1.5(1.2-1.9)$ \\
\hline Number of neutrophils $\left(10^{9} / 1\right)$ & $5.5(4.3-7.6)$ \\
\hline Number of thrombocytes $\left(10^{9} / 1\right)$ & $267.5(233.5-318.5)$ \\
\hline $\operatorname{IgA}(\mathrm{g} / \mathrm{l})$ & $3.9(2.5-5.3)$ \\
\hline $\operatorname{IgG}(\mathrm{g} / \mathrm{l})$ & $11.9(8.6-13.8)$ \\
\hline $\operatorname{IgM}(g / 1)$ & $0.8(0.5-1.1)$ \\
\hline C3 (g/l) & $1.2(1.1-1.4)$ \\
\hline $\mathrm{C} 4(\mathrm{~g} / \mathrm{l})$ & $0.3(0.2-0.3)$ \\
\hline
\end{tabular}

BVAS, Birmingham vasculitis activity score; C3, complement 3; C4, complement 4; CRP, C-reactive protein; ESR, erythrocyte sedimentation rate; GIT, gastrointestinal tract; Ig, immunoglobulin performed using SPSS statistical software package version 22.0 and Graph Pad Prism software 5.03. All tests were twotailed and $p$ values of $<0.05$ were regarded as statistically significant.

\section{Results}

\section{Characteristics of IgAV patients}

Sixty-two IgAV patients (52\% males) with median $\left(\mathrm{Q}_{25}-\mathrm{Q}_{75}\right)$ age of 56.0 (38.9-74.8) years were recruited in the study. Patients were included after a median $\left(\mathrm{Q}_{25}-\mathrm{Q}_{75}\right)$ duration of symptoms of 10 (5-19) days. All patients presented with skin purpura (necrotic $45 \%$, generalized 56\%). Joint, GIT, and renal involvement were present in $40 \%, 39 \%$, and $35 \%$, respectively (Table 1).

\section{Routine laboratory findings}

Results of routine laboratory tests are present in Table 1 . Sera levels of IgA were elevated in 29/62 (47\%) of patients above $4 \mathrm{~g} / \mathrm{l}$.

\section{Inflammatory cytokine profile}

Levels of SAA (12-fold), an acute phase protein with cytokine-like properties, IL-6 (3-fold), IL-8 (2-fold), and TNF- $\alpha$ (2-fold) were statistically significantly elevated in sera of IgAV patients compared to HBDs (Table 2). IL-1 $\beta$, IL-9, IL-10, and IL-23 were found to be unchanged in IgAV patients compared to HBDs (Table 2) and concentrations of IL-2 and IL-17A could not be determined due to their levels below the limits of detection of this assay.

Table 2 Cytokine profile in sera of adult IgAV patients compared to healthy blood donors

\begin{tabular}{|c|c|c|c|}
\hline \multirow[b]{2}{*}{ Cytokines (pg/ml) } & \multicolumn{2}{|l|}{$\operatorname{MEDIAN}\left(\mathrm{Q}_{25}-\mathrm{Q}_{75}\right)$} & \multirow[b]{2}{*}{$p$ value } \\
\hline & HBD & IgAV & \\
\hline IL-1 $\beta$ & $0.4(0.4-0.4)$ & $0.4(0.4-1.5)$ & ns \\
\hline IL-8 & $53.3(10.9-195.0)$ & $117.1(29.3-443.9)$ & 0.018 \\
\hline IL-9 & $19.0(19.0-19.0)$ & $19.0(19.0-19.0)$ & ns \\
\hline IL-10 & $1.0(0.8-2.8)$ & $0.04(0.04-1.3)$ & ns \\
\hline IL-23 & $1.4(1.4-82.9)$ & $1.4(1.4-118.6)$ & ns \\
\hline TNF- $\alpha$ & $3.9(0.8-15.5)$ & $8.1(3.0-20.2)$ & 0.003 \\
\hline IL-6 (ng/ml) & $2.0(1.0-6.0)$ & $6.0(2.8-14.3)$ & 0.015 \\
\hline SAA $(\mu \mathrm{g} / \mathrm{ml})$ & $2.8(1.9-4.7)$ & $32.8(7.2-168.0)$ & $<0.0001$ \\
\hline
\end{tabular}

$P$ values below 0.05 are deemed significant, so all 4 (IL-8, TNF-alpha, IL-6 and SAA) were significant and are thus written in bold HBD, healthy blood donors; IgAV, patients with immunoglobulin A vasculitis; SAA, serum amyloid A 
Fig. 1 Cellular immunophenotyping in HBD (a) and IgAV patients (b) Median percentages are presented of neutrophils, T-lymphocytes, Blymphocytes, NK cells, and monocytes in $\operatorname{HBD}(n=15)$ and IgAV patients $(n=15)$; HBD, healthy blood donors; IgAV, immunoglobulin A vasculitis; NK, natural killer
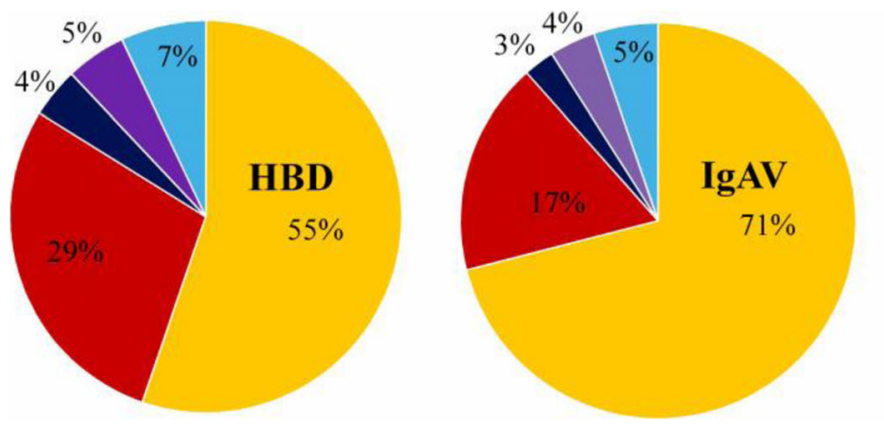

- Neutrophils

- T-lymphocytes

- B-lymphocytes

= NK-cells

- Monocytes

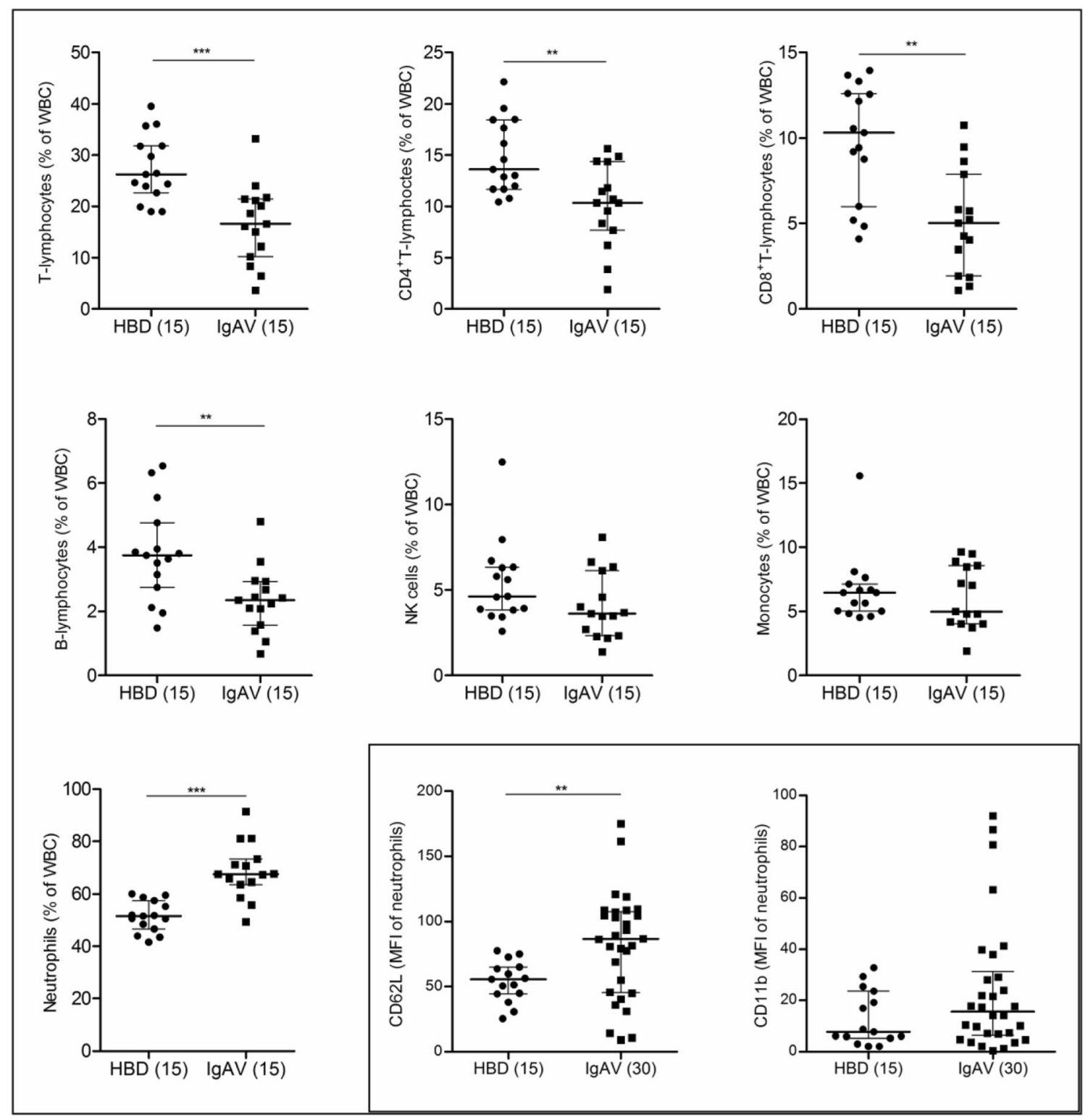

Fig. 2 Cell profiles and neutrophil surface protein expression in adult IgAV patients as compared to HBD. Medians with $\mathrm{Q}_{25}-\mathrm{Q}_{75}$ are shown for percentages of T-lymphocytes, $\mathrm{CD}^{+}$T-lymphocytes, $\mathrm{CD}^{+} \mathrm{T}$ lymphocytes, B-lymphocytes, NK cells, monocytes, neutrophils, and median fluorescence intensity of CD62L and CD11b expression on
$\mathrm{CD} 16^{+}$neutrophils. Numbers of IgAV patients and HBD are indicated in brackets; $* * p<0.01 ; * * * p<0.001$. IgAV, patients with immunoglobulin A vasculitis; HBD, healthy blood donors; NK, natural killer cells; MFI, median fluorescence intensity 
a

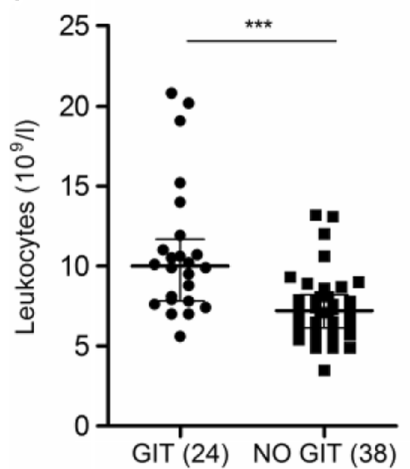

b

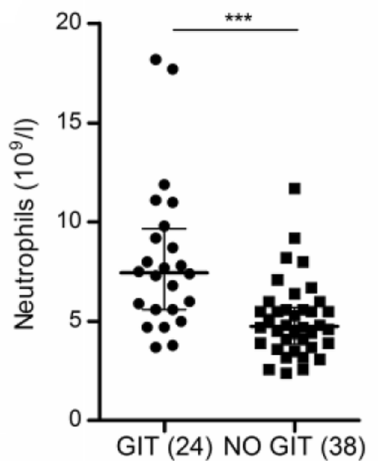

C

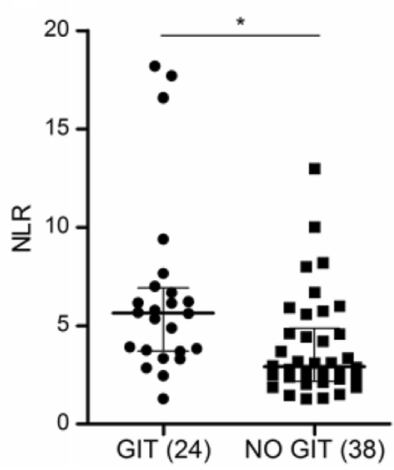

d

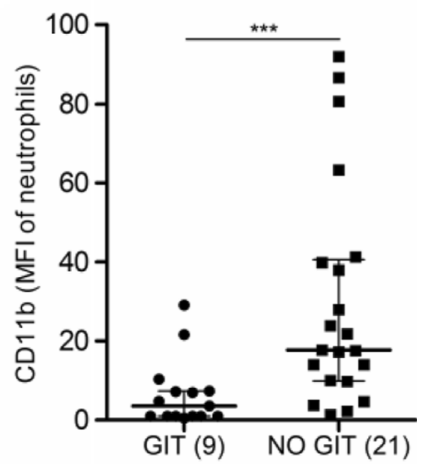

Fig. 3 Number of leukocytes, neutrophils, NLR, and CD11b neutrophil expression in IgAV patients with GIT involvement as compared to patients without GIT involvement. Medians with $\mathrm{Q}_{25}-\mathrm{Q}_{75}$ are shown for number of leukocytes a, neutrophils $\mathbf{b}$, ratio between \# of neutrophils and lymphocytes $\mathbf{c}$, and median fluorescence intensity for

\section{Inflammatory cell profile and neutrophil phenotype}

In peripheral blood of IgAV patients, there was a higher percentage of $\mathrm{CD}^{+} 6^{+}$neutrophils $(p<0.001)$ and lower percentages of $\mathrm{CD}^{+}(p<0.001)$, including $\mathrm{CD}^{+}(p=0.003)$ and $\mathrm{CD}^{+}(p=0.002)$ T-lymphocytes and $\mathrm{CD} 20^{+}$B-lymphocytes $(p=0.006)$, as compared to HBDs (Figs. 1 and 2; Supplemental Table 1). IgAV neutrophils showed significantly higher L-selectin (CD62L) surface expression with a median $\left(\mathrm{Q}_{25}-\mathrm{Q}_{75}\right)$ of $86.5(45.4-107.5)$ vs. 55.5 (44.3-64.9) $p=$ 0.008 in HBDs (Fig. 2; Supplemental Table 1).

IgAV patients with GIT involvement showed a significantly higher number of leukocytes $(p<0.0001)$, neutrophils $(p=$ 0.001 ), and calculated neutrophil to lymphocyte ratio (NLR) $(p=0.02)$, while showing lower neutrophil CD11b expression $(p=0.005)$, as compared to IgAV patients without GIT involvement (Fig. 3; Supplemental Table 2).

NLR positively correlated with SAA levels $(r=0.603$, 95\% CI $=0.410-0.744, p<0.0001)$ and neutrophil CD11b expression showed good positive correlation with sera levels of $\operatorname{IgA}(r=0.514,95 \% \mathrm{CI}=0.177-0.743, p<0.01)$ (Fig. 4).

$\mathrm{CD} 11 \mathrm{~b}$ expression on $\mathrm{CD} 16^{+}$neutrophils d. Numbers of included IgAV patients are indicated in brackets. ${ }^{*} p<0.05 ; * * p<0.01 ; * * * p<0.001$. GIT, gastrointestinal tract; IgAV, patients with immunoglobulin A vasculitis; NLR, neutrophil to lymphocyte ratio; MFI, median fluorescence intensity

\section{Discussion}

IgAV was thought to be mainly the disease of children; however, it can frequently occur in adults [4] whose disease course is usually more severe as compared to children [16]. Age, gender, and extent of purpura seem to forecast outcomes of IgA vasculitis in adults [17], but prompt diagnosis and identification of patients at risk, are a considerable challenge for clinicians, with no clinically useful laboratory biomarkers available to date [14].

Serological reports in IgAV have indicated dysregulated inflammatory cytokine production and elevated acute phase proteins. Namely, increased levels of systemic SAA (36-fold) were previously found in IgAV pediatric patients $[18,19]$ and associated with GIT manifestations [18]. The current report exposes significantly elevated levels of SAA (12-fold) in the sera of adult IgAV patients, indicating a low-medium inflammatory response.

While Th1-, as well as Th2-related cytokines, have been extensively studied in pediatric IgAV patients [19-23], data available on the adult population are scarce. Berthelot et al.
Fig. 4 Correlation between NLR and SAA concentration (a) and neutrophil CD11b expression and IgA levels (b) in IgAV patients.

Shown are Spearman correlation coefficient (r), 95\% confidence interval, $p$ value, and numbers of included patients. CI, confidence interval; IgA, patients with immunoglobulin A vasculitis; NLR, neutrophil to lymphocyte ratio; MFI, median fluorescence intensity; SAA; serum amyloid A
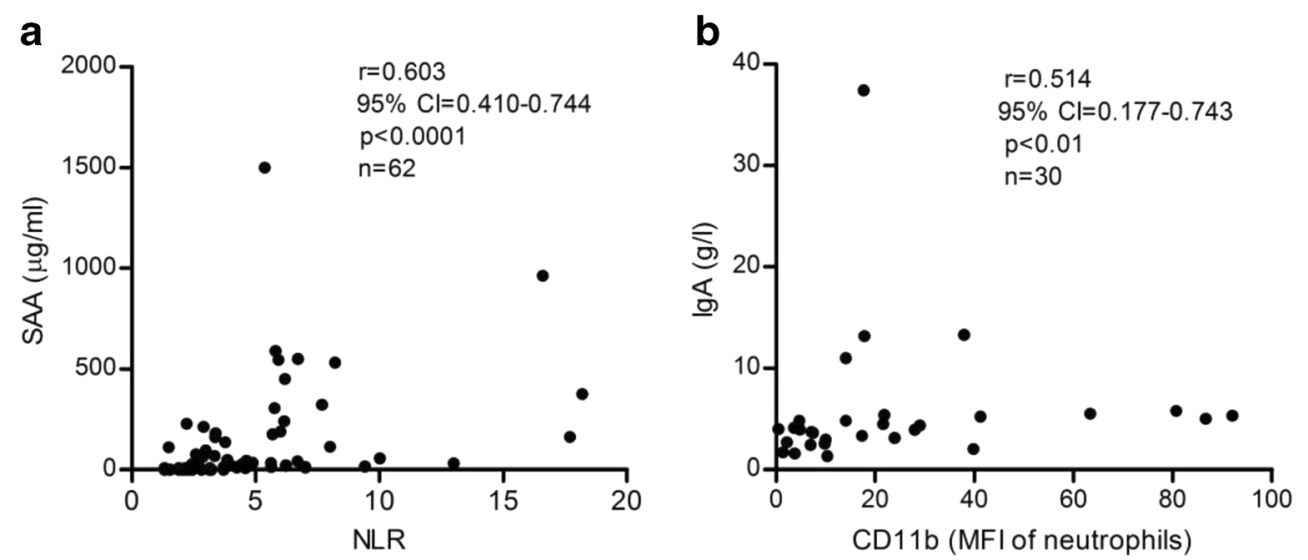
recently found higher concentrations of IL- $1 \beta$, IL- 6 , and IL-8 in the sera of adult IgAV patients, whereas levels of IL-10, IL12 p 70 , and TNF- $\alpha$ were similar between patients and control group [24]. Similarly, another study also reported on higher levels of IL-6 and IL-8 in IgAV patients, which were associated with GIT and renal involvement, respectively [25]. In the current study, we observed increased levels of proinflammatory cytokines IL- 6 , IL- 8 , and TNF- $\alpha$ in the sera of adult IgAV compared to HBDs; however, there was no association with clinical signs and symptoms.

Together with elevated sera concentrations of $\operatorname{IgA}$ and higher percentages of neutrophils, our results support the theory of the central role of IgA, endothelial cells, and neutrophils in IgAV pathogenesis, as recently reviewed in Heineke et al. [26]. Although, the origin and specific antigen targets of IgA remain unknown, these antibodies were found to bind antigens on the surface of endothelial cells [27], such as $\beta_{2}$-glycoprotein I [21] and phosphatidylserine [25]. IgA binding to endothelial cells, together with the systemic inflammatory environment (with elevated IL-6 and SAA) promote endothelial activation and production of IL-8 [28, 29], a major chemoattractant for neutrophils leading to their recruitment and activation [26]. Indeed, SAA has been shown to induce paracrine IL-8 via Toll-like receptor 2, synergizing to recruit neutrophils [30]. In addition, increased levels of TNF- $\alpha$ in the sera of IgAV patients could further accelerate inflammation, as this cytokine can enhance binding of antibodies to endothelial cells and further induce IL8 release [21, 29]. Moreover, IgA bound to Fc receptors (Fc $\alpha \mathrm{RI})$ on neutrophils, leads to antibody-dependent cell-mediated cytotoxicity (ADCC) and production of reactive oxygen species. Thus, the cross-talk between IgA, endothelial cells, and neutrophils, even in a low inflammatory environment, can lead to substantial vascular damage [26].

We also found elevated expression of L-selectin (CD62L), an adhesion molecule expressed on neutrophils, that could be involved in early pathological events of IgAV, since it is important for the initial adhesion of neutrophils to vascular surfaces [31]. Indeed, a prominent role for neutrophils, with an escaped proinflammatory phenotype was previously proposed for another systemic vasculitis [32], with both neutrophil markers $\mathrm{CD} 62 \mathrm{~L}$ and $\mathrm{CD} 11 \mathrm{~b}$ indicating progression of the disease.

Interestingly, in our study, CD11b expression was elevated in IgAV and showed good positive correlation with IgA levels. CD11b (in complex with CD18 is named Mac-1) represents a predominant $\beta_{2}$ integrin expressed on neutrophils. Mac-1 is not only important for firm adhesion of neutrophils to endothelial cells [33], but also plays a role in ADCC by interacting with $\mathrm{Fc}$ receptors on neutrophils [34]. This could indicate an independent pathogenic mechanism in $\mathrm{IgAV}$, since increased levels of IgA and CD11b expression could lead to enhanced $\mathrm{ADCC}$ and vascular damage. On the other hand, the current report also shows a negative association of neutrophil CD11b expression with GIT involvement. Migration of neutrophils across cellular barriers, such as vascular endothelium and epithelium occurs due to the effects of chemoattractants and celladhesion molecule interactions; however it seems, through different mechanisms. Specifically, neutrophils can also migrate across the intestinal epithelium using a CD11b/CD18independent mechanism [35], as suggested through the CD47 interaction with the signal regulatory protein $\alpha[36,37]$. It is therefore possible that neutrophils use different adhesion molecules to enter the site of inflammation in GIT of patients with $\mathrm{IgAV}$, requiring a neutrophil phenotype distinct from the one observed in patients with skin limited involvement.

\section{Conclusion}

Taken together, and to the best of our knowledge, this is the first study to date to determine both, serological and cellular markers in histologically-proven adult treatment-naïve IgAV. We confirmed the association of the NLR with GIT involvement [38-41] that could be a viable marker in the future. Neutrophils and their surface molecules (CD62L and $\mathrm{CD} 11 \mathrm{~b}$ ), in the presence of low-medium grade inflammation, may all contribute to the vicious cycle of IgAV pathogenesis.

Acknowledgements We would especially like to thank Prof. Mauro Peretti and Dr. Suchita Nadkarni from WHRI, Queen Mary, University of London for their support in the neutrophil experiments. We acknowledge Biomedis M.B./Biomedica gruppe for kindly providing the AtheNa Multi-Lyte Luminex xMAP Technology needed to perform the multiplex cytokine experiments.

Funding information This study received financial support from the Slovene Research Agency (ARRS) for the National Research Program P3-0314.

\section{Compliance with ethical standards}

Disclosures None.

Ethical approval and consent to participate Ethical approval for the study was obtained by the Slovenian National Medical Ethics Committee (\#99/04/15 and \#65/01/17).

Open Access This article is distributed under the terms of the Creative Commons Attribution 4.0 International License (http:// creativecommons.org/licenses/by/4.0/), which permits unrestricted use, distribution, and reproduction in any medium, provided you give appropriate credit to the original author(s) and the source, provide a link to the Creative Commons license, and indicate if changes were made.

\section{References}

1. Jennette JC, Falk RJ, Bacon PA, Basu N, Cid MC, Ferrario F, Flores-Suarez LF, Gross WL, Guillevin L, Hagen EC, Hoffman GS, Jayne DR, Kallenberg CG, Lamprecht P, Langford CA, Luqmani RA, Mahr AD, Matteson EL, Merkel PA, Ozen S, 
Pusey CD, Rasmussen N, Rees AJ, Scott DG, Specks U, Stone JH, Takahashi K, Watts RA (2013) 2012 revised international chapel hill consensus conference nomenclature of vasculitides. Arthritis Rheum 65(1):1-11. https://doi.org/10.1002/art.37715

2. Penny K, Fleming M, Kazmierczak D, Thomas A (2010) An epidemiological study of Henoch-Schonlein purpura. Paediatr Nurs 22(10):30-35. https://doi.org/10.7748/paed2010.12.22.10.30. c8135

3. Piram M, Mahr A (2013) Epidemiology of immunoglobulin A vasculitis (Henoch-Schonlein): current state of knowledge. Curr Opin Rheumatol 25(2):171-178. https://doi.org/10.1097/BOR. 0b013e32835d8e2a

4. Hocevar A, Rotar Z, Ostrovrsnik J, Jurcic V, Vizjak A, Dolenc Voljc M, Lindic J, Tomsic M (2014) Incidence of IgA vasculitis in the adult Slovenian population. Br J Dermatol 171(3):524-527. https:// doi.org/10.1111/bjd.12946

5. Pillebout E, Thervet E, Hill G, Alberti C, Vanhille P, Nochy D (2002) Henoch-Schonlein purpura in adults: outcome and prognostic factors. J Am Soc Nephrol 13(5):1271-1278

6. Calvo-Rio V, Loricera J, Mata C, Martin L, Ortiz-Sanjuan F, Alvarez L, Gonzalez-Vela MC, Gonzalez-Lamuno D, RuedaGotor J, Fernandez-Llaca H, Gonzalez-Lopez MA, Armesto S, Peiro E, Arias M, Gonzalez-Gay MA, Blanco R (2014) HenochSchonlein purpura in northern Spain: clinical spectrum of the disease in 417 patients from a single center. Medicine 93(2):106-113. https://doi.org/10.1097/MD.0000000000000019

7. Garcia-Porrua C, Calvino MC, Llorca J, Couselo JM, GonzalezGay MA (2002) Henoch-Schonlein purpura in children and adults: clinical differences in a defined population. Semin Arthritis Rheum 32(3):149-156. https://doi.org/10.1053/sarh.2002.33980

8. Lu S, Liu D, Xiao J, Yuan W, Wang X, Zhang X, Zhang J, Liu Z, Zhao Z (2015) Comparison between adults and children with Henoch-Schonlein purpura nephritis. Pediatr Nephrol 30(5):791796. https://doi.org/10.1007/s00467-014-3016-z

9. Kang Y, Park JS, Ha YJ, Kang MI, Park HJ, Lee SW, Lee SK, Park YB (2014) Differences in clinical manifestations and outcomes between adult and child patients with Henoch-Schonlein purpura. J Korean Med Sci 29(2):198-203. https://doi.org/10.3346/jkms. 2014.29.2.198

10. Audemard-Verger A, Pillebout E, Guillevin L, Thervet E, Terrier B (2015) IgA vasculitis (Henoch-Shonlein purpura) in adults: diagnostic and therapeutic aspects. Autoimmun Rev 14(7):579-585. https://doi.org/10.1016/j.autrev.2015.02.003

11. Audemard-Verger A, Terrier B, Dechartres A, Chanal J, Amoura Z, Le Gouellec N, Cacoub P, Jourde-Chiche N, Urbanski G, Augusto JF, Moulis G, Raffray L, Deroux A, Hummel A, Lioger B, Catroux M, Faguer S, Goutte J, Martis N, Maurier F, Riviere E, Sanges S, Baldolli A, Costedoat-Chalumeau N, Roriz M, Puechal X, Andre M, Lavigne C, Bienvenu B, Mekinian A, Zagdoun E, Girard C, Berezne A, Guillevin L, Thervet E, Pillebout E (2017) Characteristics and management of IgA vasculitis (HenochSchonlein) in adults: data from 260 patients included in a French multicenter retrospective survey. Arthritis Rheumatol 69(9):18621870. https://doi.org/10.1002/art.40178

12. Ozen S, Pistorio A, Iusan SM, Bakkaloglu A, Herlin T, Brik R, Buoncompagni A, Lazar C, Bilge I, Uziel Y, Rigante D, Cantarini L, Hilario MO, Silva CA, Alegria M, Norambuena X, Belot A, Berkun Y, Estrella AI, Olivieri AN, Alpigiani MG, Rumba I, Sztajnbok F, Tambic-Bukovac L, Breda L, Al-Mayouf S, Mihaylova D, Chasnyk V, Sengler C, Klein-Gitelman M, Djeddi D, Nuno L, Pruunsild C, Brunner J, Kondi A, Pagava K, Pederzoli S, Martini A, Ruperto N (2010) EULAR/PRINTO/PRES criteria for Henoch-Schonlein purpura, childhood polyarteritis nodosa, childhood Wegener granulomatosis and childhood Takayasu arteritis: Ankara 2008. Part II: final classification criteria. Ann Rheum Dis 69(5):798-806. https://doi.org/10.1136/ard.2009.116657
13. Hocevar A, Rotar Z, Jurcic V, Pizem J, Cucnik S, Vizjak A, van den Broeke R, Tomsic M (2016) IgA vasculitis in adults: the performance of the EULAR/PRINTO/PRES classification criteria in adults. Arthritis Res Ther 18:58. https://doi.org/10.1186/s13075016-0959-4

14. Hetland LE, Susrud KS, Lindahl KH, Bygum A (2017) HenochSchonlein purpura: a literature review. Acta Derm Venereol 97(10): 1160-1166. https://doi.org/10.2340/00015555-2733

15. Hong J, Yang HR (2015) Laboratory markers indicating gastrointestinal involvement of Henoch-Schonlein purpura in children. Pediatr Gastroenterol Hepatol Nutr 18(1):39-47. https://doi.org/ 10.5223/pghn.2015.18.1.39

16. Hung SP, Yang YH, Lin YT, Wang LC, Lee JH, Chiang BL (2009) Clinical manifestations and outcomes of Henoch-Schonlein purpura: comparison between adults and children. Pediatr Neonatol 50(4):162-168. https://doi.org/10.1016/S1875-9572(09)60056-5

17. Hocevar A, Rotar Z, Jurcic V, Cucnik S, Tomsic M (2015) Patient age, gender and extent of purpura may suggest short-term outcomes in adults with IgA vasculitis. Rheumatology (Oxford) 54(7):1330 1332. https://doi.org/10.1093/rheumatology/kev122

18. He X, Zhao Y, Li Y, Kang S, Ding Y, Luan J, Zhao P, Liu N, Yin W (2012) Serum amyloid a levels associated with gastrointestinal manifestations in Henoch-Schonlein purpura. Inflammation 35(4): $1251-1255$

19. Purevdorj N, Mu Y, Gu Y, Zheng F, Wang R, Yu J, Sun X (2018) Clinical significance of the serum biomarker index detection in children with Henoch-Schonlein purpura. Clin Biochem 52:167170. https://doi.org/10.1016/j.clinbiochem.2017.11.006

20. Besbas N, Saatci U, Ruacan S, Ozen S, Sungur A, Bakkaloglu A, Elnahas AM (1997) The role of cytokines in Henoch Schonlein purpura. Scand J Rheumatol 26(6):456-460

21. Yang YH, Chang CJ, Chuang YH, Hsu HY, Yu HH, Lee JH, Wang LC, Lin YT, Chiang BL (2012) Identification and characterization of IgA antibodies against beta2-glycoprotein I in childhood Henoch-Schonlein purpura. Br J Dermatol 167(4):874-881. https://doi.org/10.1111/j.1365-2133.2012.11068.x

22. Pan YX, Ye Q, Shao WX, Shang SQ, Mao JH, Zhang T, Shen HQ, Zhao N (2014) Relationship between immune parameters and organ involvement in children with Henoch-Schonlein purpura. PLoS One 9(12):e115261. https://doi.org/10.1371/journal.pone.0115261

23. Pillebout E, Jamin A, Ayari H, Housset P, Pierre M, Sauvaget V, Viglietti D, Deschenes G, Monteiro RC, Berthelot L (2017) Biomarkers of IgA vasculitis nephritis in children. PLoS One 12(11):e0188718. https://doi.org/10.1371/journal.pone.0188718

24. Berthelot L, Jamin A, Viglietti D, Chemouny JM, Ayari H, Pierre M, Housset P, Sauvaget V, Hurtado-Nedelec M, Vrtovsnik F, Daugas E, Monteiro RC, Pillebout E (2017) Value of biomarkers for predicting immunoglobulin a vasculitis nephritis outcome in an adult prospective cohort. Nephrol Dial Transplant. https://oi.org/ 10.1093/ndt/gfx300

25. Kimura S, Takeuchi S, Soma Y, Kawakami T (2013) Raised serum levels of interleukins 6 and 8 and antiphospholipid antibodies in an adult patient with Henoch-Schonlein purpura. Clin Exp Dermatol 38(7):730-736. https://doi.org/10.1111/ced.12089

26. Heineke MH, Ballering AV, Jamin A, Ben Mkaddem S, Monteiro RC, Van Egmond M (2017) New insights in the pathogenesis of immunoglobulin a vasculitis (Henoch-Schonlein purpura). Autoimmun Rev 16(12):1246-1253. https://doi.org/10.1016/j. autrev.2017.10.009

27. Yang YH, Wang SJ, Chuang YH, Lin YT, Chiang BL (2002) The level of IgA antibodies to human umbilical vein endothelial cells can be enhanced by TNF-alpha treatment in children with HenochSchonlein purpura. Clin Exp Immunol 130(2):352-357

28. Yang YH, Lai HJ, Huang CM, Wang LC, Lin YT, Chiang BL (2004) Sera from children with active Henoch-Schonlein purpura can enhance the production of interleukin 8 by human umbilical 
venous endothelial cells. Ann Rheum Dis 63(11):1511-1513. https://doi.org/10.1136/ard.2003.016196

29. Yang YH, Huang YH, Lin YL, Wang LC, Chuang YH, Yu HH, Lin YT, Chiang BL (2006) Circulating IgA from acute stage of childhood Henoch-Schonlein purpura can enhance endothelial interleukin (IL)-8 production through MEK/ERK signalling pathway. Clin Exp Immunol 144(2):247-253. https://doi.org/10.1111/j.13652249.2006.03076.x

30. De Buck M, Berghmans N, Portner N, Vanbrabant L, Cockx M, Struyf S, Opdenakker G, Proost P, Van Damme J, Gouwy M (2015) Serum amyloid A1alpha induces paracrine IL-8/CXCL8 via TLR2 and directly synergizes with this chemokine via CXCR2 and formyl peptide receptor 2 to recruit neutrophils. J Leukoc Biol 98(6):10491060. https://doi.org/10.1189/jlb.3A0315-085R

31. Liu Z, Yago T, Zhang N, Panicker SR, Wang Y, Yao L, MehtaD'souza P, Xia L, Zhu C, McEver RP (2017) L-selectin mechanochemistry restricts neutrophil priming in vivo. Nat Commun 8: 15196. https://doi.org/10.1038/ncomms 15196

32. Nadkarni S, Dalli J, Hollywood J, Mason JC, Dasgupta B, Perretti M (2014) Investigational analysis reveals a potential role for neutrophils in giant-cell arteritis disease progression. Circ Res 114(2): 242-248. https://doi.org/10.1161/CIRCRESAHA.114.301374

33. Anderson SI, Hotchin NA, Nash GB (2000) Role of the cytoskeleton in rapid activation of $\mathrm{CD} 11 \mathrm{~b} / \mathrm{CD} 18$ function and its subsequent downregulation in neutrophils. J Cell Sci 113(Pt 15):27372745

34. van Spriel AB, Leusen JH, van Egmond M, Dijkman HB, Assmann KJ, Mayadas TN, van de Winkel JG (2001) Mac-1 (CD11b/CD18) is essential for Fc receptor-mediated neutrophil cytotoxicity and immunologic synapse formation. Blood 97(8):2478-2486
35. Blake KM, Carrigan SO, Issekutz AC, Stadnyk AW (2004) Neutrophils migrate across intestinal epithelium using beta2 integrin (CD11b/CD18)-independent mechanisms. Clin Exp Immunol 136(2):262-268. https://doi.org/10.1111/j.1365-2249. 2004.02429.x

36. Parkos CA, Colgan SP, Liang TW, Nusrat A, Bacarra AE, Carnes DK, Madara JL (1996) CD47 mediates post-adhesive events required for neutrophil migration across polarized intestinal epithelia. J Cell Biol 132(3):437-450

37. Liu Y, Buhring HJ, Zen K, Burst SL, Schnell FJ, Williams IR, Parkos CA (2002) Signal regulatory protein (SIRPalpha), a cellular ligand for CD47, regulates neutrophil transmigration. J Biol Chem 277(12):10028-10036. https://doi.org/10.1074/jbc.M109720200

38. Nagy GR, Kemeny L, Bata-Csorgo Z (2017) Neutrophil-tolymphocyte ratio: a biomarker for predicting systemic involvement in adult IgA vasculitis patients. J Eur Acad Dermatol Venereol : JEADV 31(6):1033-1037. https://doi.org/10.1111/jdv.14176

39. Park CH, Han DS, Jeong JY, Eun CS, Yoo KS, Jeon YC, Sohn JH (2016) The optimal cut-off value of neutrophil-to-lymphocyte ratio for predicting prognosis in adult patients with Henoch-Schonlein purpura. PLoS One 11(4):e0153238. https://doi.org/10.1371/ journal.pone. 0153238

40. Makay B, Gucenmez OA, Duman M, Unsal E (2014) The relationship of neutrophil-to-lymphocyte ratio with gastrointestinal bleeding in Henoch-Schonlein purpura. Rheumatol Int 34(9):1323-1327. https://doi.org/10.1007/s00296-014-2986-2

41. Gayret OB, Erol M, Tekin Nacaroglu H (2016) The relationship of neutrophil-lymphocyte ratio and platelet-lymphocyte ratio with gastrointestinal bleeding in Henoch-Schonlein purpura. Iran J Pediatr 26(5):e8191. https://doi.org/10.5812/ijp.8191 